\title{
Fenomena Akuntabilitas Terhadap Pendanaan Lembaga Swadaya Masyarakat
}

\section{Bramasta Noviantoro Putro dan Paskah Ika Nugroho}

Fakultas Ekonomika dan Bisnis Universitas Kristen Satya Wacana (UKSW) Salatiga J1. Diponegoro No. 52-60 Salatiga 50711, Indonesia

Info Article Abtract

Keywords:

Downward accountability; NGO

Accountability; Local NGOs;

NGO Funding; NGO Programs

ISSN (print) : 2598-7763

ISSN (online): 2598-7771

$\triangle$ Corresponding Author: Bramasta Noviantoro Putro: Tel. /Fax. +62 822-2114-0838 E-mail:

bramastanoviantoro@gmail.com

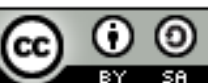

\section{PENDAHULUAN}

Lembaga Swadaya Masyarakat (LSM) adalah organisasi berbasis kemasyarakatan berdasarkan kesamaan kehendak, aspirasi, kebutuhan, kepentingan kegiatan, dan bertujuan untuk berpartisipasi dalam pembangunan (Mahardika, 2012). Goddard (2006) menyatakan bahwa LSM mempunyai pengaruh dalam perkembangan sosial serta intervensi ekonomi di seluruh dunia. Agyemang, O’Dwyer, and Unerman (2019) me- ngemukakan bahwa peran LSM mempunyai peranan penting terkait pelayanan kepada warga sipil dengan pemerintah setempat dengan membantu segala masalah masyarakat termasuk kemiskinan merupakan salah satu masalah yang selalu diulang dalam era modern saat ini.

Terkait isu yang sering dihadapi oleh LSM, isu pendanaan dan akuntabilitas merupakan hal yang paling banyak muncul. Pendanaan merupakan masalah yang kompleks bagi setiap LSM baik yang berskala kecil maupun besar. LSM mem- 
peroleh segala jenis pendanaan dari luar negeri seperti World Bank, Lembaga Donor Nasional seperti Ford Foxundation, dan pendanaan dari pemerintah dan individu serta dari anggota organisasi itu sendiri (Ali, 2016). Masalah umum yang dihadapi adalah timbulnya ketergantungan LSM kepada para pemberi dana asing.

Perihal pendanaan dalam LSM tidak dapat terlepas dari pentingnya akuntabilitas LSM terhadap pemberi dana. Dalam hal akuntabilitas, sebuah LSM dituntut untuk memaparkan berbagai informasi pendanaan sampai pengeluaran kegiatan proyek yang sudah maupun belum terealisasikan kepada pemangku kepentingan (stakeholder) terutama masyarakat miskin. Tujuan dari akuntabilitas secara umum adalah untuk meyakinkan penerima dana bahwa LSM tersebut sudah memenuhi kewajibannya terhadap pemberi dana. Namun, sebagian besar LSM menolak memberikan informasi baik secara lengkap maupun sebagian kepada pihak tertentu. Zadek (2003) berpendapat bahwa LSM tidak bersedia memaparkan informasi organisasi mereka adalah karena prestasi dan niat baik mereka dianggap sudah cukup menjadi dasar akuntabilitas. Di sisi lain, Lee (2004) pendanaan juga mempengaruhi tingkat akuntabilitas terutama jika pendanaan yang di peroleh dari suatu pihak terutama dari pihak pemerintah akan mempengaruhi pihak donatur. Dalam hal ini legimitasi dari sebuah LSM dipertanyakan.

Bagi LSM, trust (kepercayaan) mempunyai peran penting untuk meyakinkan penggalangan dana dari berbagai pihak. Tingkat kepercayaan atas kinerja LSM di Indonesia cenderung berfluktuatif. Menurut data dari Edelman barometer sejak tahun 2015 hingga tahun 2018 tingkat kepercayaan publik terhadap LSM cenderung mengalami penurunan. Berbeda dengan tingkat kepercayaan publik terhadap tiga institusi publik lainnya seperti bisnis, media dan sektor publik masih lebih tinggi jika dibandingkan dengan LSM. Penulis mengamati bahwa tingkat kepercayaan di Indonesia pantas dikatakan baik, namun kondisi LSM secara global sedang mengalami krisis kepercayaan. Hal ini harus menjadi perhatian utama, khususnya Indonesia karena krisis kepercayaan ini akan menghambat pendanaan (Fund) dari para pendonor, terutama pendonor asing dari negara lain. Agar akuntabilitas LSM di Indonesia lebih baik lagi ada beberapa syarat, menurut Antlov (2005), yaitu Funding Agencies (pemberi dana) harus mulai menyadari bahwa akuntabilitas bukan hanya sebatas pelaporan keuangan, tetapi para pendonor perlu menerima standar akuntabilitas yang tinggi dari publik.

Pentingnya Trust Issues yang ada pada saat ini sedang dihadapi LSM yang berlokasi di Nusa Tenggara Timur (NTT) yang berada di bawah pengawasan pemerintah Australia bernama Nusa Tenggara Association (NTA) Incorporated. NTA sudah berdiri sejak tahun 1988 yang merupakan hasil dari kerja sama antara Pemerintah Australia dengan Indonesia dalam menumpas kemiskinan dan masalah kemarau panjang yang terjadi di NTT (YouTube ACFID, 2018). Dalam menjalankan setiap kegiatan proyek yang ada, NTA menerima donasi terbesar dari pihak Pemerintah Federal Australia melalui DFAT (Department of Foreign Affairs and Trade) yaitu departemen luar negeri dan perdagangan Australia yang dikelola secara langsung oleh ANCP (Australian NGO Cooperation Program).

Menurut penelitian Uddin \& Belal (2019) para donor menetapkan dan menuntut akuntabilitas atau transparasi informasi terkait implementasi program untuk memverifikasi kesesuaian pendanaan. LSM yang bersangkutan jika tidak dapat mematuhinya pendanaan akan dihentikan.

Tujuan dibuatnya penelitian ini adalah untuk menginvestigasi fenomena pendanaan serta akuntabilitas LSM yang didanai oleh Pemerintah Federal Australia yang melakukan pembangunan masyarakat di wilayah Nusa Tenggara Timur yaitu Flores, Kupang dan Timor Barat. Hal pendanaan dan akuntabilitas sekarang ini menjadi persoalan kritis di dunia yang mengakibatkan LSM mengalami kendala dalam menjalankan tugas serta tanggung jawabnya dalam memberikan pelayanan kepada masyarakat umum.

Dalam hal menjawab research question, penulis menerapkan studi kualitatif dan studi kasus dengan melibatkan wawancara dengan narasumber seputar akuntabilitas dari LSM Australia. Narasumber adalah auditor dan accounting advisor dari LSM Australia tersebut dan mema-parkan perihal akuntabilitas di LSM sesuai dengan pengalamannya bekerja di LSM Australia sejak 2006 hingga saat ini.

\section{PENGEMBANGAN KERANGKA PENELI- TIAN}

Lembaga swadaya masyarakat (LSM) atau Non-Government Organization (NGO) merupakan suatu organisasi yang didirikan oleh seorang ataupun sekelompok orang yang secara sukarela membantu dalam bentuk pelayanan kepada ma- 
syarakat tanpa bertujuan untuk memperoleh keuntungan (not-for-profit) dari kegiatan tersebut. LSM memiliki instrumen hukum yaitu UndangUndang Nomor 8 Tahun 1985 tentang Organisasi Kemasyarakatan. instrumen hukum lainnya adalah Instruksi Menteri Dalam Negeri Nomor 8 tahun 1990 tentang Pembinaan LSM. NTA adalah LSM yang bekerja sama dengan LSM di Indonesia diantaranya Yayasan Pengembangan Pulau Masyarakat Semau (YPMPS) di Timor barat dan Yayasan Pengembangan Masyarakat Flores (YPMF) di Flores. NTA berperan dalam Pembangunan, kemiskinan, pendidikan, dan ekonomi di NTT dan Flores NTA bekerja sama dengan YPPS dan YPMF dengan menyalurkan dana hibah ke sasaran yang tepat.

\section{Pemberi dan Dana Hibah}

Dalam melaksanakan kegiatan yang ada, LSM memerlukan banyak dana, oleh karena itu peran pendonor sangat penting. Sumber dana LSM didapat dari banyak pihak Donor baik di dalam maupun di luar negeri, yaitu sumbangan individu/masyarakat (filantropi), APBN/APBD dari pemerintah, lembaga donor internasional (Ford Foundation), lembaga pembangunan internasional, pemerintah luar negeri, LSM luar negeri yang memiliki kerja sama dengan LSM dalam negeri bahkan melalui usaha ekonomi LSM itu sendiri.

Di Indonesia rata-rata penerimaan sumbangan dana berasal dari luar negeri. Penelitian yang dilakukan oleh Ibrahim (2010) pada 25 Organisasi Sumberdaya Masyarakat Sipil (OSMS) menghasilkan bahwa mayoritas lembaga non profit masih mengandalkan sumber dana dari luar negeri yang mencapai 65 persen, sementara sumber dalam negeri 35 persen. Secara lebih rinci, sumber dalam negeri ini terutama adalah hasil usaha sendiri 33 persen, sumbangan perusahaan dan dana abadi masing-masing 17 persen, donasi individu (filantropi) menyumbang 14 persen, sisanya dalam jumlah yang kecil bersumber dari APBD/APBN dari pemerintah 5 persen, sumbangan ORNOP 3 persen, dan sumber lainnya 11 persen.

LSM memiliki cara masing-masing untuk menerima maupun menolak donor. Ada yang menolak donor dari World bank di sebabkan jika ada ketimpangan pembangunan akibat hutang yang dipinjamkan, ada juga yang menolak APBD/APBN dikarenakan jika diterima maka independensi dalam mengkritik kinerja pemerintah akan terpengaruh. Peraturan dalam menerima maupun menolak segala pihak pendonor tidak disebutkan dalam undang-undang sehingga memberikan kebebasan bagi LSM dalam memilih dan memanajemen pendanaan yang ada.

NTA memiliki beberapa pendonor dan sebagian besar berlokasi Australia seperti DFAT, Rotary Club, lembaga Filantropi, perusahaan dan Masyarakat secara umum, selain itu NTA juga menerima donor dari DFAT Indonesia untuk program WASH. NTA menerima dana dari DFAT 1 tahun sekali berdasarkan grant, NTA juga menerima dana hibah dari Rotary Club dibeberapa kota di Australia untuk membantu pembangunan infastruktur dan pendidikan.

\section{Funding}

Menurut Assa'di (2009) Pendanaan merupakan bagian penting bagi keberlangsungan LSM, yaitu untuk kebutuhan pelaksanaan kegiatan, operasional, gaji, dan lainnya. Oleh karena itu, LSM memprioritaskan pendanaan sebagai aspek penting bagi eksistensi lembaga. Fakih (2000) menyatakan bahwa LSM mengalami ketergantungan yang besar terhadap para pendonor terutama pendonor dari luar negeri. Dana yang diterima bisa berupa hibah tetapi ada juga yang bersifat sebagai hutang negara.

Uhlin (1997) berpendapat bahwa dana bantuan, baik hibah ataupun hutang negara banyak menimbulkan masalah. Masalah pertama adalah ketergantungan, hal ini disebabkan karena sejak tahun 1970 sampai sekarang aliran dana yang didapat dari berbagai kalangan mengalir sangat deras terutama dari luar negeri sehingga sering disebut sebagai Easy Money. Dampaknya, para pengurus LSM menggantungkan segala kegiatan mereka baik yang sedang terlaksana maupun belum kepada pemberi dana terutama dari luar negeri. Sedangkan dari berbagai pengalaman yang sudah dihadapi oleh banyak LSM pendanaan dari luar negeri tidak dapat selalu berkelanjutan (sustainable). Masalah kedua adalah tidak dapat terlaksananya sebagian kegiatan yang sudah direncanakan oleh LSM dikarenakan Organisasi tersebut selalu mengikuti arah keinginan dari pemberi dana (donor driven).

Pada penelitian ini diyakini bahwa Pendanaan (DN) sangat tergantung pada Akuntabilitas (AK) sebuah LSM. Selain itu Akuntabilitas (AK) akan mempengaruhi Pemberi Dana (PD) untuk memutuskan pemberian dana hibah atau Pendanaan (DN). Dalam hal ini dampak dari Akuntabilitas (AK) terhadap Pendanaan (DN) juga terjadi secara tidak langsung melalui Pemberi Dana (PD) 
(indirect effect AK terhadap DN melalui PD) (Gambar 1).

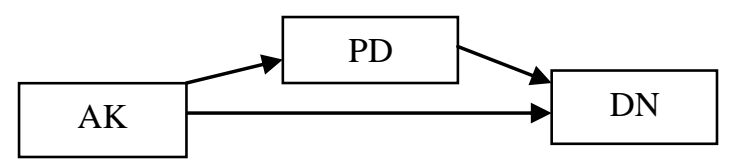

Gambar 1. Model Hubungan Akuntabilitas, Pendanaan dan Pemberi Dana

\section{DATA DAN METODE}

Penelitian ini menerapkan metode studi kasus (case study) secara kualitatif. Menurut Sugiyono (2000) penelitian kualitatif adalah penelitian yang dikhususkan untuk menyelidiki, menemukan dan menjelaskan kualitas dari kuantitatif. Pendekatan penelitian kualitatif dipilih karena diharapkan peneliti akan dapat memperoleh pemahaman mendalam mengenai fenomena yang menjadi fokus penelitian (Baxter dan Jack, 2008).

Penggunaan metode kualitatif yang digunakan dalam penelitian ini bertujuan untuk menganalisa fenomena akuntabilitas pada pendanaan yang terjadi pada LSM NTA. Data primer diperoleh melalui wawancara sementara data sekunder yang diperoleh adalah berupa laporan kegiatan dan laporan keuangan, serta kegiatan yang sudah maupun belum terealisasikan yang didapat langsung dari LSM NTA. Wawancara akan dilakukan dengan narasumber yang berposisi sebagai Auditor dan Accounting Advisor yang sudah bekerja di NTA dari tahun 2006-sekarang. Data yang diperoleh dapat menunjukan aktivitas penggunaan pendanaan dari para pemberi hibah dan menunjukan tingkat akuntabilitas dari LSM tersebut. Analisis dilakukan berdasarkan wawancara. Langkah analisis data meliputi tahapan pengumpulan data, reduksi data, verifikasi dan penarikan kesimpulan.

\section{HASIL}

\section{Karakteristik LSM NTA}

NTA adalah LSM yang dibentuk oleh Australia dan Indonesia selama survei besar tentang potensi sosial-ekonomi Provinsi Nusa Teng-gara Timur pada tahun 1988. NTA dimiliki oleh Australia yang berpusat di Ibu Kota Australia tepatnya kota Canberra ACT (Australia Capital Territo$r y$ ). NTA diatur oleh dewan-dewan yang berbasis di Canberra ACT. Dibawah dewan-dewan terdapat 3 komite yaitu Komite Keuangan, Komite Operasi dan Keanggotaan dan Komite pemasaran. Komite tersebut mengembangkan kebijakan dan menjalankan fungsi di bawah arahan dewan. NTA menjalankan misi kemanusiaan di kepulauan NTT, NTA bekerja sama dengan LSM yang berada di NTT yaitu Yayasan Pengembang-an Pulau Masyarakat Semau (YPMPS) di Timor barat dan Yayasan Pengembangan Masyarakat Flores (YPMF) di Flores, NTA bekerja sama de-ngan YPPS dan YPMF dengan menyalurkan dana hibah ke sasaran yang tepat. NTA berperan dalam hal Pembangunan, kemiskinan, pendidikan, dan ekonomi di NTT dan Flores NTA dengan berfokus pada 3 program yaitu: 1) Proyek Aglicultural dan lainnya (termasuk menganyam syal ikat ikat unik di kawasan tertentu) yang bertujuan untuk meningkatkan pendapatan mereka. 2) Pemanenan dan penggunaan air tawar melalui pembangunan tangki air hujan dan sumur di luar atap untuk meningkatkan hasil kesehatan dan serta infrastruktur skala kecil lainnya termasuk pagar untuk ternak dan penyediaan toilet rumah tangga. 3) Bantuan untuk sekolah dan guru-guru berupa buku-buku perpustakaan dan pelatihan dan pemberian beasiswa untuk anak-anak dari keluarga yang sangat miskin.

Dalam melaksanakan semua program-progam yang ada, NTA memiliki beberapa pendonor yang memberi donasi besar diantaranya adalah pihak Pemerintah Federal Australia dan DFAT (Department of Foreign Affairs and Trade).

NTA memfokuskan diri kepada 2 bentuk akuntabilitas LSM yaitu upward accountability dan downward accountability seperti yang telah ditulis oleh Stecher dan Kirby (2004). Upward accountability dalam LSM adalah mengenai bagaimana sebuah LSM mempertanggung jawabkan segala proyek-proyek yang mereka jalankan kepada para pemberi dana. Sementara downward accountability adalah tanggung jawab sebuah LSM kepada masyarakat (Masdar, 2015). Kestabilian dari penerimaan dana hibah memiliki korelasi langsung dengan akuntabilitas (direct correlation).

Upward accountability menurut narasumber adalah Pemerintah memiliki peranan penting dalam menentukan persetujuan pemberian dana hibah kepada NTA. Berikut ini adalah pendapat yang disampaikan oleh narasumber:

"NTA harus mengajukan permohonan dana hibah (grant) kepada Pemerintah Federal Australia guna mendanai proyek-proyek pembangunan di Flores, Kupang dan Timor Barat. NTA menerima dana bantuan dari Pemerintah Federal Australia yang dalam hal ini adalah DFAT (Department of Foreign Affair and Trade atau departemen luar ne-geri dan perdagangan Australia) dengan metode matching-grant, 
yang mana setiap \$1 dana yang dihasilkan dari penggalangan dana NTA maka Pemerintah Australia akan memberikan tiga kali lipat. Dengan demikian, berkat bantuan dana hibah dari Pemerintah Federal Austral$i a$, dana pembangunan NTA di Indonesia Timur menjadi lebih besar dan semakin banyak desa terpencil yang menerima bantuan dalam rangka memperbaiki taraf hidup mereka. Setiap tahunnya NTA harus melaporkan seluruh biaya pembangunan proyek di NTT kepada Pemerintah Federal Australia dalam bentuk acquittal report. Selain itu NTA juga melaporkan penggunaan dana untuk proyek-proyek pembangunan di desa miskin di NTT kepada donor lainnya seperti Rotary Club, kelompok masyarakat dan individual di Australia. Secara rutin NTA melakukan presentasi dan pelaporan kepada donor lainnya serta menerima aspirasi dari masyarakat Australia untuk membantu mengurangi dampak kemiskinan terhadap penduduk desa miskin di NTT. Inilah bentuk upward accountability dari NTA terhadap DFAT dan donor "lainnya"

Sedangkan terkait downward accountability narasumber berpendapat bahwa kerjasama dan koordinasi dengan LSM local (Yayasan) adalah salah satu bentuk downward accountability yang efektif dalam melaksanakan semua proyek- proyek dilakukan oleh NTA. Berikut adalah pendapat dari narasumber terkait downward accountability:

"NTA melakukan proyek-proyek pembangunan kemanusiaan di desa-desa terpencil di wilayah Flores, Kupang dan Timor Barat. Di sana NTA bekerja sama dengan LSM lokal yang bernama Yayasan Pengembangan Masyarakat Flores (YPMF) dan Yayasan Pengembangan Masyarakat Pulau Semau (YPMPS). Selain itu, NTA juga membuka kantor NTA Kupang sebagai kepanjangan tangan dari NTA Pusat di Canberra, Aus-tralia. Tugas dari YPMF dan YPMPS adalah mempersiapkan proposal pembangunan yang dia-jukan oleh para anggota masyarakat di desa terpencil di NTT yang dihasilkan dari musyawarah. Selain itu yayasan juga melaporkan biaya-biaya proyek pembangunan ini kepada NTA Pusat melalui NTA Kupang. Laporan dari Yayasan kemudian diperiksa oleh Manajemen NTA di Canberra dan Auditor /Accounting Adviser. Setiap tahun Manajemen NTA dan Petugas Pemeriksa NTA melakukan kunjungan penilikan (monitoring visit) pada bulan Mei dan November untuk memastikan seluruh dana hibah digunakan sesuai dengan proposal pembangunan proyek yang sudah disetujui. Seluruh laporan proyek disimpan di penyimpanan arsip di NTA Pusat di Canberra. Demikianlah bentuk downward accountability NTA terhadap masyarakat dan yayasan di Flores, Kupang dan Timor Barat".

Sebagai tambahan narasumber juga menyinggung mengenai stabilitas penerimaan dana hibah untuk proyek-proyek pembangunan NTA. Hal ini didukung oleh tabel rasio dana hibah yang diterima dan juga rasio gaji. Ini menunjukan kredibilitas dan reputasi NTA dimata pemberi dana hibah (pemerintah dan donor lainnya)

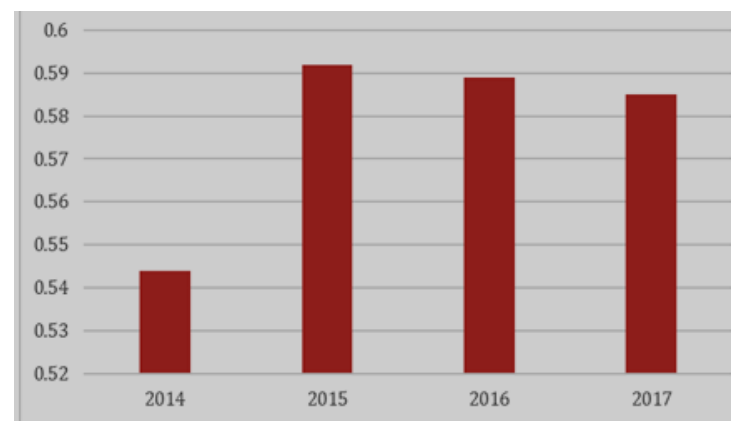

Gambar 2. Rasio Biaya Proyek Terhadap Dana Hibah NTA

Berdasarkan gambar 2 dapat disimpulkan bahwa pergerakan rasio biaya proyek terhadap dana hibah NTA cukup stabil sejak 2015-2017 bahkan mengalami penurunan. Ini berarti bahwa biaya proyek pembangunan NTA mengalami penu-runan sebagai akibat dari efisiensi dan pengelolaan proyek yang sangat baik oleh para relawan. Disisi lain penerimaan dana hibah mengalami peningkatan

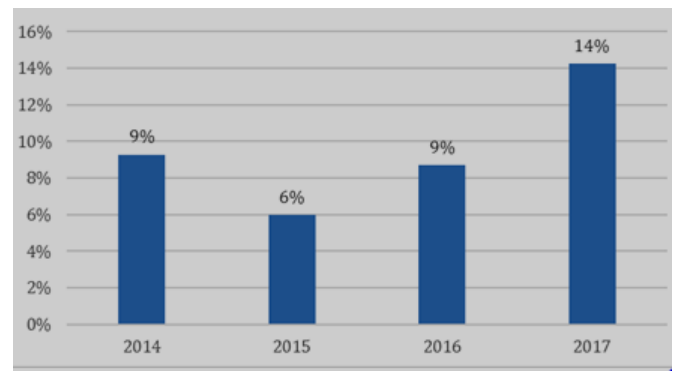

Gambar 3. Rasio Gaji Yang Diberikan

Biaya gaji yang diberikan bukan diperuntukan pegawai NTA pusat di Canberra melainkan untuk staff dan karyawan di NTA Kupang yang seluruhnya adalah putera daerah NTT (local resources), penyebab terjadi kenaikan rasio gaji adalah karena adanya penyesuaian gaji untuk membantu para karyawan dalam masalah krisis ekonomi dan inflasi di Indonesia. Penyesuaian gaji ini disesuaikan secara berkala sesuai dengan iklim Ekonomi di Indonesia dan di Dunia.

\section{PEMBAHASAN}

\section{Posisi Penerimaan Dana Hibah}

Dana hibah memiliki peran yang sangat penting bagi LSM dalam melaksanakan segala 
kegiatan. Selama ini dana hibah yang diterima oleh NTA mengalami peningkatan yang cukup stabil. Berikut adalah penjelasan dari narasumber mengenai dana hibah yang diterima NTA:

"Selama ini NTA menerima dana hibah dari DFAT (dahulu bernama AusAID) untuk mendanai pembangunan proyek-proyek di NTT. Dari tabel diatas dapat dilihat peningkatan peneri-maan dana hibah dari DFAT dan donor lainnya. Hal ini menunjukkan bahwa NTA memiliki kredibilitas yang cukup tinggi di mata pemberi dana hibah seperti DFAT dan donor lainnya. Tingkat kredibilitas tinggi ini didukung oleh tertib administrasi keuangan NTA dan penye-rapan dana yang maksimal untuk pembangunan. Selain itu, di desa-desa terpencil di NTT telah terjadi perubahan yang sangat signifikan dan peningkatan taraf hidup yang sangat baik."

Terkait dengan stabilitas biaya mengenai proyek NTA narasumber berpendapat bahwa depresiasi nilai tukar rupiah atau IDR memberi dampak positif terhadap biaya pembangunan NTA. Hal ini mengakibatkan biaya-biaya pembangunan masih dalam koridor anggaran. Berikut ini adalah penjelasan detail dari narasumber:

"Biaya pembangunan proyek NTA di desa-desa terpencil di NTT dapat dinilai stabil sekalipun nilai tukar Rupiah (IDR) mengalami depresiasi cukup besar terhadap Dollar Australia (AUD) selama beberapa dekade. Hingga saat data dan informasi NTA dikumpulkan, seluruh biaya pem-bangunan proyek NTA dinilai stabil dan tidak mengalami perubahan yang signifikan. Namun demikian masyarakat miskin di Flores, Kupang dan Timor Barat merasakan perubahan taraf hidup yang sangat signifikan pada beberapa dekade terakhir ini. Pembangunan di desa-desa miskin di NTT ini terdiri dari pembangunan di bidang infrastruktur kecil, peningkatan penda-patan masyarakat dan pendidikan. Selain itu tentu saja pembangunan sarana penampungan air dan sanitasi serta kesehatan masyarakat".

\section{Mempertahankan Akuntabilitas NTA Dimata Pemberi Dana}

Narasumber berpendapat bahwa mempertahankan akuntabilitas NTA dimata pemberi dana hibah, terutama pemerintah Australia adalah hal yang tidak mudah, berbagai proses administratif dan audit yang harus dipenuhi oleh NTA agar dapat menerima dana hibah tersebut. Narasumber menjelaskan NTA berhasil lulus akreditasi DFAT dari 2007:

"Untuk dapat menerima dana hibah dari DFAT (AusAID) setiap tahunnya, NTA harus melalui proses akreditasi ketat yang dilakukan oleh Pemerintah $\mathrm{Fe}$ deral Australia. Persyaratan akreditasi mencakup bi- dang operasional, manajemen, keuangan dan akuntabilitas dari NTA. Akreditasi diadakan oleh Pemerintah Federal Australia setiap lima tahun sekali terhadap seluruh LSM Australia yang mengadakan proyek pembang-unan kemanusiaan di luar negeri dan bertaraf internasional. Tim NTA bekerjasama secara ber-gotong royong, baik para relawan NTA di Australia maupun di Kupang. Seluruh data, informasi dan laporan dikirimkan ke Pemerintah Federal untuk selanjutnya dilakukan pemeriksaan (desk audit) dan wawancara oleh Petugas dari DFAT. NTA adalah anggota dari ACFID (Australian Council For International Development) yang adalah lembaga payung yang mengawasi dan memantau kegiatan seluruh LSM Australia yang mengadakan proyek pembangunan kemanusiaan non-pemerintah di luar negeri. NTA tergolong sebagai LSM kecil menengah di dalam kategori LSM ACFID yang dinilai sangat baik oleh ACFID dan DFAT dalam menjalankan misi kemanusiaan di Indonesia bagian Timur".

\section{Prestasi NTA dimata ACFID}

Di bulan Agustus 2018 NTA dipilih oleh ACFID untuk mewakili seluruh LSM dalam kategori kecil menengah Australia yang telah berhasil menjalankan Quality Principle 3 Code of Conduct karena telah mewujudkan prinsip kualitas pembangunan dengan benar dan bertanggung jawab. Fakta ini telah direkam di dalam video YouTube pada situs https;//youtu.be/h2 136w ZUI"

\section{NTA Dimata Masyarakat Miskin di NTT.}

Dari video YouTube diatas dapat disimpulkan bahwa NTA telah melalui proses yang cukup panjang dalam mengadakan pembangunan masyarakat miskin di NTT (Flores, Kupang dan Timor Barat) selama tiga dekade. Kedewasaan dan kematangan NTA sebagai sebuah LSM Australia yang berusaha meningkatkan taraf hidup masyarakat miskin di desa-desa terpencil di NTT telah terbukti dengan tercatatnya peningkatan di berbagai bidang kemasyarakatan seperti pendidikan, pertanian, peternakan, perkebunan, usaha kecil, dan kesehatan.

Dampak positif yang ditinggalkan oleh NTA terhadap desa-desa miskin di daerah terpencil di NTT dirasakan sangat besar dan sangat signifikan. Inilah gambaran akuntabilitas NTA di mata masyarakat miskin di NTT.

\section{Proses Alokasi Dana Proyek Pembangunan NTA}

Narasumber berpendapat bahwa musyawarah adalah cara yang efektif dalam menen- 
tukan sasaran alokasi dana. Berikut adalah penjelasan dari narasumber:

"Setiap tahun NTA mengadakan rapat musyawarah yang diadakan di balai desa bersama masyarakat desa miskin di Flores, Kupang dan Timor Barat. Tim NTA Australia bertindak sebagai panel yang mendengarkan aspirasi dari kelompok-kelompok masyarakat NTT yang diajukan pada setiap sesi musyawarah. Setiap kelompok diberikan kesempatan untuk melakukan presentasi proyek yang mereka usulkan seperti misalnya pembangunan penampungan/bak air (water tank), toilet, pagar, perpustakaan, pengadaan buku, pelatihan pustakawan (librarian), pelatihan petani dan peternak, dan lain sebagainya. Selain itu, NTA juga mengadakan program kredit dana bergulir (rotating credit) untuk membantu masyarakat miskin dalam menjalankan usaha kecil dengan memberikan pinjaman dana bergulir tanpa bunga bagi kelompok-kelompok masyarakat yang beranggotakan 10 orang, Setiap enam bulan NTA Pusat dan NTA Kupang memeriksa progres pengembalian dari dana bergulir ini. Berdasarkan dari Dari 10 orang anggota kelompok, hanya satu anggota saja yang boleh meminjam setiap periodenya dan sebelum anggota tersebut melunasi hutang dana bergulir ini, maka anggota lainnya tidak diperbolehkan untuk melakukan pinjaman."

Proses verifikasi pengiriman dana NTA ke Flores Kupang Timur Barat. Narasumber ikut ambil bagian dalam merencanakan dan mengatur system pengiriman dari Australia ke Indonesia. Berikut ini adalah uraian penjelasan dari narasumber:

"Dari hasil musyawarah dan proyek-proyek yang disetujui oleh NTA, dana hibah diki-rimkan ke masyarakat miskin di NTT melalui NTA Kupang. Pengiriman dana hibah dijadwalkan oleh NTA Pusat di Canberra berdasarkan rapat dewan eksekutif (Executive Committee) NTA di dalam pertemuan anggaran proyek pembangunan. Pengiriman dana hibah ke NTA Kupang dilakukan secara berkala atas persetujuan dari dewan eksekutif. Selanjutnya NTA Kupang melaporkan kepada NTA Pusat tentang penerimaan dana yang nantinya akan dilengkapi dengan laporan persetujuan pembiayaan (agreed disbursement). Setelah sebuah proyek selesai, maka YPMF dan YPMPS akan melaporkan seluruh kegiatan proyek kepada NTA Pusat melalui NTA Kupang. Seluruh laporan penggunaan dana hibah diperiksa oleh dewan eksekutif dan auditor/ accounting adviser NTA".

\section{Sistem Pengawasan Alokasi Dana Hibah NTA.}

Menurut narasumber, alokasi dana diawasi oleh board dan dewan eksekutif NTA di Canberra dan narasumber sendiri sebagai auditor dan accounting advisor. Berikut penjelasan narasumber: "Alokasi dana hibah yang telah disetujui di musyawarah diawasi secara seksama oleh board dan dewan eksekutif NTA terutama dalam hal penggunaannya dan kesesuaian dengan proposal yang telah disetujui. Setiap alokasi dana hibah juga diperiksa oleh auditor $\mathcal{E}$ accounting adviser. Pengawasan dan penilikan dilaporkan di dalam rapat dewan setiap bulan".

\section{Bentuk Upward dan Downward Accountability NTA}

Menurut narasumber, upward accoun-tability NTA kepada DFAT adalah dalam bentuk acquittal report/laporan penggunaan dana. Berikut penjelasan dari narasumber:

"NTA diwajibkan untuk melaporkan kegiatannya ke ACNC (Australian Charities and Not-forprofit Commission) yaitu lembaga Pemerintah Federal Australia yang membawahi 56.000 LSM sosial kemanusiaan Australia. NTA juga diwajibkan melaporkan pajak ke ATO (Australian Tax Office atau Kantor Pajak Australia) dari hasil pengumpulan dana hibah (grant) dan sumbangan dari donor lainnya. Laporan dari NTA kepada Pemerintah Federal Australia sangat menentukan per-olehan dana hibah untuk mendanai proyekproyek pembangunan di NTT. Laporan ini berupa laporan kegiatan dan proyek NTA di NTT beserta laporan keuangan dan pertumbuhan ekonomi daerah terpencil sebagai dampak dari misi pembangunan NTA di NTT."

Disisi lain narasumber berpendapat bahwa downward accountability NTA adalah dalam wujud laporan pembangunan proyek didalam rapat musyawarah kepada masyarakat dan pemerintah. Berikut penjelasan lebih lanjut dari narasumber: "Sedangkan progres dan pencapaian pembangu-nan desa-desa miskin NTA di NTT dilaporkan oleh masyarakat secara berkelompok melalui YPMF dan YPMPS dan disampaikan kepada NTA Pusat melalui NTA Kupang. Setiap bulan YPMF dan YPMPS mengirimkan laporan progres pembangunan desa-desa miskin di NTT. Setiap enam bulan sekali yayasan merangkum seluruh pencapaian dan progres pembangunan dalam laporan kegiatan (activity report) dan mengirimkannya ke NTA Pusat melalui NTA Kupang. Pada saat yang sama, setiap enam bulan sekali, tim dari NTA Canberra akan datang ke NTT un-tuk melakukan pemeriksaan langsung dan penilikan dari 
proyek-proyek pembangunan sesuai dengan proposal yang diajukan oleh masyarakat setempat."

\section{Hal-hal yang Menjadi Pertimbangan Dana Hi- bah Untuk Membantu NTA Dalam Pembiayaan Proyek Pembangunan di NTT}

Narasumber berpendapat bahwa dampak positif dari proyek pembangunan NTA terhadap pertumbuhan ekonomi dan sosial di desa-desa pelosok NTT merupakan penentu utama pemberian dana hibah. Berikut penjelasan dari narasumber:

"Pemerintah Federal Australia melihat dampak positif dari proyek pembangunan desa-desa ter-pencil di NTT selama tiga dekade dan memberikan apresiasi yang sangat besar kepada NTA yang telah meningkatkan pertumbuhan ekonomi dan sosial di daerah tersebut. Secara berkala NTA melaporkan setiap pertumbuhan ekonomi dan sosial yang mengubah peradaban di daerah terpencil di NTT dari kehidupan masyarakat yang sederhana menjadi komunitas yang mengikuti perkembangan zaman dan teknologi kompu-ter. Dari sisi pendidikan, NTA telah mendirikan taman kanakkanan dan lembaga PAUD (pendidikan anak usia dini) agar anak-anak setempat dapat memulai langkah awal belajar mereka di sekolah selama dekade terakhir ini. Sebelumnya pada dua dekadi pertama misi NTA di NTT tidak ada TK ataupun PAUD di wilayah terpencil ini. Hal ini membawa perubahan besar bagi generasi muda NTT terutama anak-anak kecil yang akan mulai memasuki dunia pendidikan sekolah. Dari sisi pertanian dan perkebunan, NTA membantu para petani di desa-desa terpencil dalam me-ngembangkan usaha pertanian dan perkebunan cokelat/kakao (cocoa) dan jambu mete (cashew nut) sebagai peninggalan masa penjelajahan samudera Pemerintah Portugis di wilayah timur Indonesia sejak abad ke enam belas".

Kinerja dan Perfomansi NTA Dalam Pembangunan Di Wilayah Flores Kupang Timor Barat.

Narasumber menjelaskan bahwa kinerja dan perfomansi NTA di Indonesia timur dinilai sangat baik oleh Pemerintah Federal Australia. Berikut penjelasan dari narasumber:

"Pemerintah Federal Australia melalui DFAT dan ACNC menilai kineja dan performansi NTA di dalam pembangunan di wilayah Indonesia Timur tertumana Flores, Kupang dan Timor Barat sangat berarti, signifikan dan berdampak positif bagi masyarakat miskin di wilayah tersebut. Oleh karena itu dana hibah dari DFAT terus mengalir dan menjadi salah satu sumber dana hibah terbesar bagi NTA bernilai ratusan ribu dollar Australia (AUD) setiap tahunnya. Selain itu NTA telah memenuhi persyaratan akreditasi DFAT selama ini dan secara rutin dan berkesinam-bungan menerima dana hibah dari Pemerintah Federal Australia."

\section{Dukungan Dari Pemberi Hibah dan Donor Lainnya.}

Narasumber berpendapat bahwa baik Lembaga filantropi, perorangan ataupun Rotary Club menilai bahwa NTA telah memberikan dampak yang positif terhadap pertumbuhan sosial, budaya, Pendidikan dan ekonomi di NTT. Berikut penjelasan lebih lanjut dari narasumber:

"Baik lembaga filantropi dan Rotary Club mau-pun peorangan menilai bahwa NTA adalah se-buah LSM yang memiliki kredibilitas yang tinggi dan telah menjalankan misinya dengan sangat baik. Saat ini NTA didukung oleh Rotary Club dari berbagai kota di Australia seperti Canberra, Sydney (New South Wales), Adelaide (South Australia), Darwin (Northern Teritory) dan Melbourne (Victoria) yang telah memberikan dana hibah bernilai puluhan ribu dollar Australia (AUD). Bantuan ini dialokasikan pada pembangunan bak air, toilet, perpustakaan, fasilitas seko-lah dan usaha kecil masyarakat desa. Selain itu, akademisi dari beberapa universitas di Australia juga melibatkan diri sebagai relawan untuk membantu misi pembangunan NTA dengan cara memberikan pelatihan dan berbagi pengetahuan serta pengalaman dalam berbagai bidang seperti teknologi pertanian, perkebunan, peternakan, pengololaan sekolah, perpustakaan, usaha kecil-me-nengah, dan lain-lain."

\section{SIMPULAN DAN SARAN}

Kesimpulan dari hasil penelitian ini adalah NTA dianggap sudah memenuhi karakteristik akuntabilitas dikarenakan mendapatkan aliran dana tetap dari para donor baik dari pihak pemerintah federal Australia, Rotary club, Kelompok Masyarakat, Individu serta dari DFAT sejak tahun 2007. Tingkat kredibilitas yang tinggi, penerapan upward, downward accountability hingga menerima prestasi dalam mewakili LSM tingkat kecil menenga oleh ACFID dapat berdampak baik dalam mendapatkan kepercayaan lebih dari para pemberi dana untuk mempertahankan pendapatan dana demi program-program NTA kedepan.

Penelitian ini dapat memperingatkan dan menjadi tolak ukur agar NTA dapat mempertahankan akuntabilitasnya yang tinggi. Keterbatasan dalam penelitian ini adalah data wawancara yang didapat hanya sesi tanya jawab dalam media online saja, sehingga hasil wawancara yang didapat kurang kompleks. Saran dari peneliti untuk penelitian selanjutnya adalah diusahakan bertatap muka secara langsung dalam sesi 
wawancara dengan narasumber agar data yang diperoleh dapat lebih maksimal serta bisa mendapat data tambahan.

\section{DAFTAR PUSTAKA}

Agyemang, G., O'Dwyer, B. and Unerman, J. (2019). NGO accountability: retrospective and prospective academic contributeons, Accounting, Auditing \& Accountability Journal, 32 (8): 2353-2366.

Ali, T. M. (2016). Government Funding to the NGOs: A Blessing or a Curse? Research in Business and Social Science. 5 (6): 51-61.

Antlov, H. (2005). Ngo Governance and Accountability in Indonesia: Challenges in A Newly Democratizing Country.

Assa'di, H. (2009). Independensi Lembaga Swadaya Masyarakat (LSM) di Tengah Kepentingan Donor. Transdisiplin Sosiologi, Komunikasi, dan Ekologi Manusia. 3 (2): 231-258.

Baxter, Pamela dan Jack, Susan. (2008). Qualitative Case Study Methodology: Study Design and Implementation for Novice Researchers. The Qualitative Report, 13 (4): 544559.

Fakih, M. (2000). Masyarakat Sipil Untuk Transformasi Sosial: Pergolakan Ideologi LSM Indonesia. Yogyakarta: INSISTPress.

Goddard, A. (2006). Accounting and Navigating Legitimacy in Tanzanian NGOs. Accounting, Auditing \& Accountability Journal. 19 (3): 377-404.

Ibrahim, R. (2010). Kode Etik LSM \& Undangundang Organisasi Masyarakat Sipil, Pengalaman Beberapa Negara. Jakarta: Sekretariat Konsil LSM Indonesia.

Lee, J. (2004). NGO Accountability: Rights and Responsibilities.

Mahardika, F. (2012). Lembaga Swadaya Masyarakat (LSM) Berdasarkan Undang-Undang Nomor 8 Tahun 1985 Tentang Organisasi Kemasyarakatan (Studi Tentang Peran Lembaga Swadaya Masyarakat (LSM) Dalam Perlindungan Perempuan Korban Tindak Pidana Kesusilaan di Purwokerto).

Masdar, Hj. Noor Muafiza. (2015). The Practices of Upward Accountability in the Malaysian NGO. International Accounting and Business Conference 2015, IABC. Procedia Economics and Finance 31: 152-160

Peraturan Menteri Dalam Negeri Nomor 8 Tahun 1990 Tentang Pembinaan Lembaga Swadaya Masyarakat.

Peraturan Menteri Dalam Negeri Nomor 8 tahun
1990 tentang Pembinaan LSM.

Stecher, Brian and Sheila Nataraj Kirby, Nataraj Sheila. (2004). Organizational improvement and accountability: lessons for education from other sectors. Rand Corporation.

Sugiyono. 2000. Metode Penelitian. Bandung: CV Alvabeta.

Uddin, M.M. and Ataur Rahman Belal, R.A. (2019). Donors' influence Strategies and Beneficiary Accountability: An NGO Case Study. Journal Accounting Forum, 43 (1)

Uhlin, A. (1997). Oposisi Berserak: Arus Deras Demokratisasi Gelombang Ketiga di Indonesia. Mizan.

Undang-Undang Nomor 16 Tahun 2001 tentang Yayasan.

Undang-Undang Nomor 8 Tahun 1985 tentang Organisasi Kemasyarakatan.

Zadek, S. (2003). In Defense of Non-Profit Accountability. 34-36. 